\title{
Removal of Estrogen from Water Using Membrane
}

\author{
Smita Mohan Tahaliyani ${ }^{1}$, Dr. Saniya Harish Lade ${ }^{2}$
}

\begin{abstract}
Estrogen contamination from products such as birth control and estrogen therapy has led to possible health concerns when consumed from drinking water sources. It is unhealthy for the human body, animals, and the environment, causing feminization in humans and the birth of more females. This paper presents the evaluation of retention of such natural estrogens as estrone (E1), estradiol (E2) and estriol (E3) as well as synthetic compounds considered to be endocrine disrupting substances(EDs) using membrane. Reverse Osmosis is used for the separation. For polyethersulphone membranes the retention of estrogens using reverse osmosis is studied in this paper.
\end{abstract}

Keywords: Membrane, Reverse osmosis, Estrogen.

\section{Introduction}

Over the past decade, a new contaminant has found its way into water supplies around the world: pharmaceutical products that contain estrogen. Estrogen comes from multiple sources, both natural and synthetic-made. It has been found to have negative effects on males and females alike when it is consumed daily in public drinking water. Not much has been done to stop this problem. Most water treatment plants have not implemented any processes to remove estrogen, and little research has been done to find the best way to solve the problem.

In an era focused on sustainability, the water industry is faced with the challenge of ensuring a sustained and safe supply of drinking water from sources of varying quality, including the reuse of wastewater. Population growth, urbanization, industrial development, and associated changes in agricultural and other land-use practices have contributed significantly to reducing water quality through naturally occurring and anthropogenic contamination.

Estrogens can enter waterways by many routes including by direct discharge into water; use of pharmaceuticals and chemicals by householders and in agriculture and industry; accidental spills and releases of compounds; and indirectly through diffuse sources such as storm water runoff. The main sources of estrogens in the rivers and lakes are sewage effluent and agricultural chemicals from runoff. In less developed countries uncontrolled domestic and industrial discharge to waterways contributes to Estrogen.

The issue of Estrogens has been an issue of global concern. The human population and associated wastewater treatment plants are considered to be the major source of these chemicals in the aquatic environment. Also, major source is believed incomplete removal in sewage treatment plants followed by discharge in the effluent. These are largely excreted from the body through urine. To minimize the potential risks to aquatic ecosystems from the discharge of municipal wastewater effluent and agricultural runoff, inexpensive treatment processes capable of removing trace concentrations of hormones are needed. Estrogens are attracting a lot of attention due to their inability to naturally biodegrade and continued prevalence in the environment as a result of consistent sizeable release. Estrogenic chemicals synthesized in pharmaceuticals are raising exposure levels in living things to the naturally occurring hormone estrogen.
This compounded exposure has been associated with breast cancer, endometriosis, birth defects, abnormal sexual development, lowered sperm counts and world-wide accounts of the feminization of male fish near sewage treatment plants.

This study has provided some insight into the removal of estrogens by membranes. The mechanisms governing rejection may vary considerably from case to case.

\section{Materials and Methods}

Estrogens or Oestrogens are a group of compounds named for their importance in both menstrual and estrous reproductive cycles. They are the primary female sex hormones. Natural estrogens are steroid hormones, while some synthetic ones are non-steroidal. Estrogen is a group of chemically similar hormones that are needed for development of female characteristics and reproduction. In reality, estrogen is produced by both men and women. The human body has three naturally occurring steroid estrogens: Estrone (E1), 17-B Estradiol (E2), and Estriol (E3). Estrogens are used as part of some oral contraceptives, in estrogen replacement therapy for postmenopausal women, and in hormone replacement therapy, also in cancer therapy and veterinary medicine. There are two types of estrogens which are steroidal and non-steroidal.

Membranes can remove reliably most trace micro pollutants depending on compound size, the chemistry conditions of the feed solution and membrane material. Several investigative studies on estrogens removal using membranes have found that size exclusion is important. Tight and small pore sized membranes (reverse osmosis (RO) and nanofiltration (NF) can achieve up to $90 \%$ removal whilst the big pore sized membranes (microfiltration and ultra filtration) did not perform well. The degree of selectivity of a membrane depends on the membrane pore size. The influent of a membrane is known as the feed-stream, the liquid that passes through the membrane is known as the permeate and the liquid containing the retained constituents is the retentate or concentrate.

Applications of reverse osmosis in the water industry are growing. RO process is particularly effective to remove trace contaminants both inorganic (such as nitrate, arsenic and fluoride) and organic (such as pesticides and other synthetic organic chemicals) and also removal of emerging 


\section{International Journal of Science and Research (IJSR) \\ ISSN (Online): 2319-7064}

Index Copernicus Value (2013): 6.14 | Impact Factor (2014): 5.611

wastewater pollutants namely pharmaceutically active compounds and steroid hormones. Reverse Osmosis is commonly used for desalination. As well, RO is commonly used for the removal of dissolved constituents from wastewater remaining after advanced treatment with microfiltration.

\subsection{Experimental Procedure:}

In this study, spiral wound membrane for reverse osmosis (RO) having $1.85 \mathrm{~m}^{2}$ area is used to remove estrogen from water, that is: RO polyethersulphone membrane.

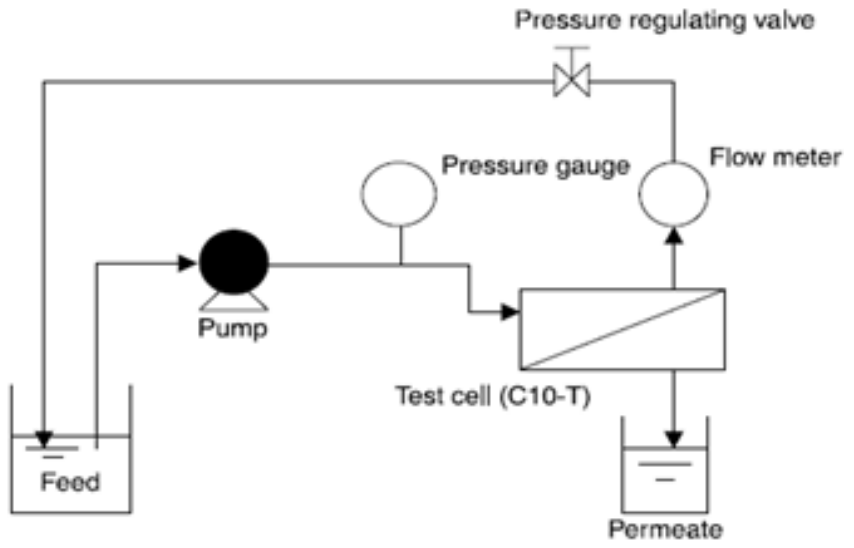

Figure: Schematic Diagram of experimental set-up

The estrogen- water solution was synthesized by dissolving conjugated estrogen tablets in distilled water. Tablets were ground to fine powder in a grinder. This powder was then dissolved in water. So the concentration of feed is $3.7352 \mathrm{mg} / \mathrm{lit}$. Then this estrogen-water solution is fed to the feed tank of capacity 25 litres. Experiments were conducted using a cross flow module. The schematic diagram of experimental set up is shown in Figure. The spiral wound polyethersulphone membrane was used having effective membrane surface area $1.85 \mathrm{~m}^{2}$. The retentate will be circulated to increase the concentration of estrogen in the feed solution. A flow meter installed in the concentrate line was used to measure the concentrate flow rate. Permeate flow was measured by a digital balance and stop watch. Permeate and retentate samples were taken. Then permeate flux and concentrations were measured.

\subsection{Mathematical Model}

The recovery rate $(\%)$ of the membrane was obtained using the formula below:

Recovery, $r(\%)=\left(\mathrm{Q}_{\mathrm{p}} / \mathrm{Q}_{\mathrm{f}}\right) * 100$

Where $Q_{p}$ is the flow rate of the permeate $(\mathrm{L} / \mathrm{min})$ and $Q_{f}$ is the low rate of the feed $(\mathrm{mL} / \mathrm{min})$. Flow rate of the feed, $\mathrm{Q}_{\mathrm{f}}$, can be obtained as follows from the corresponding mass balance equation:

$\mathrm{Q}_{\mathrm{f}}=\mathrm{Q}_{\mathrm{p}}+\mathrm{Q}_{\mathrm{c}}$

Where $\mathrm{Q}_{\mathrm{c}}$ is the flow rate of the concentrate $(\mathrm{L} / \mathrm{min})$. The rejection, $\mathrm{R}(\%)$ can be termed as the percentage of solute concentration reduction of permeate stream relative to feed stream, and can be calculated as follows:

$\mathrm{R}(\%)=\left[\left(\mathrm{C}_{\mathrm{f}}-\mathrm{C}_{\mathrm{p}}\right) / \mathrm{C}_{\mathrm{f}}\right] * 100 \%$

Where $\mathrm{R}$ is the rejection (\%), $\mathrm{C}_{\mathrm{f}}$ is the feed concentration and $\mathrm{C}_{\mathrm{p}}$ is the permeate concentration. Flux can be termed as mass or volume transfer through the membrane surface. It can be calculated as follows:

Flux $=(\mathrm{V} / \mathrm{A}) \mathrm{t}$

Where $\mathrm{V}$ is the volume of permeate $(\mathrm{m} 3), \mathrm{A}$ is the effective area of membrane $(\mathrm{m} 2)$ and $t$ is the duration $(\mathrm{min})$.

\section{Result and Discussion}

Result and discussion are presented in this section. Figure 1 shows Effect of pressure on Rejection. It is observed from this figure that as pressure increases, the \% rejection also increases. This may be due to the fact that high pressure favors high rejection.

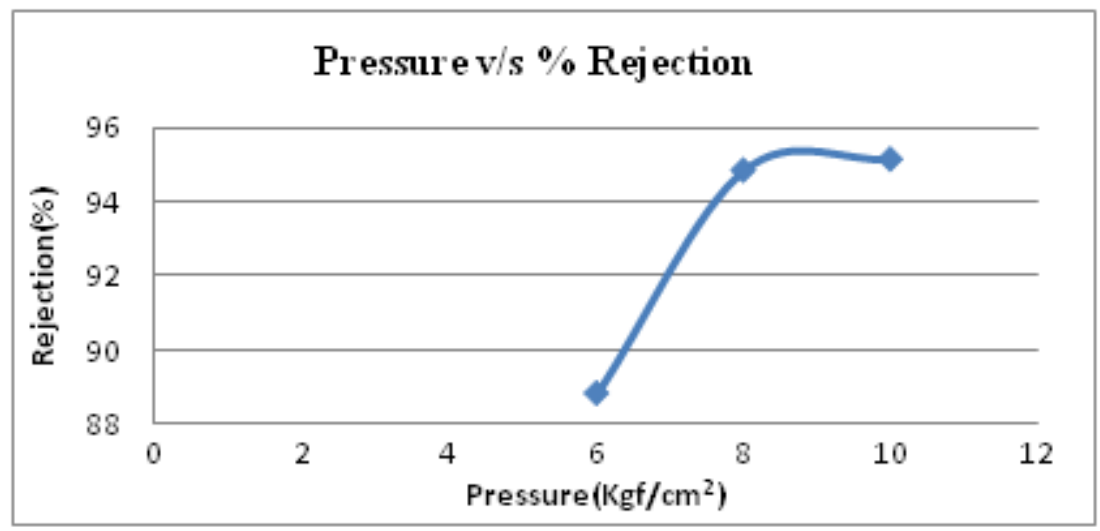

Figure 1: Effect of Pressure on Rejection

Figure 2 shows Effect of Pressure on Permeate Flux. It is observed from this figure that as pressure increases, the permeate flux decreases. 
International Journal of Science and Research (IJSR)

ISSN (Online): 2319-7064

Index Copernicus Value (2013): 6.14 | Impact Factor (2014): 5.611

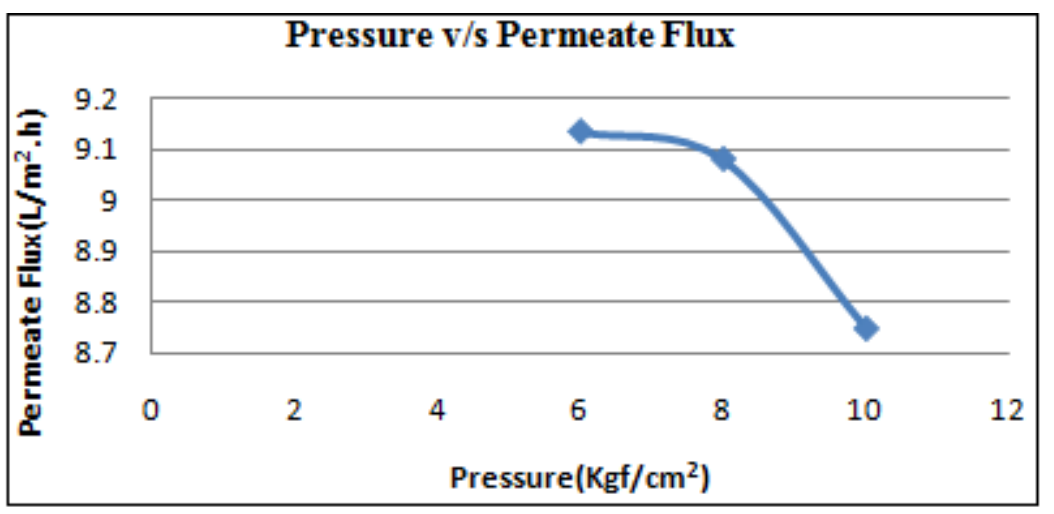

Figure 2: Effect of Pressure on Permeate Flux

Figure3 shows Effect of Pressure on volume of Permeate. It is observed from this figure that initially as pressure increases, permeate volume also increases and then decrease.

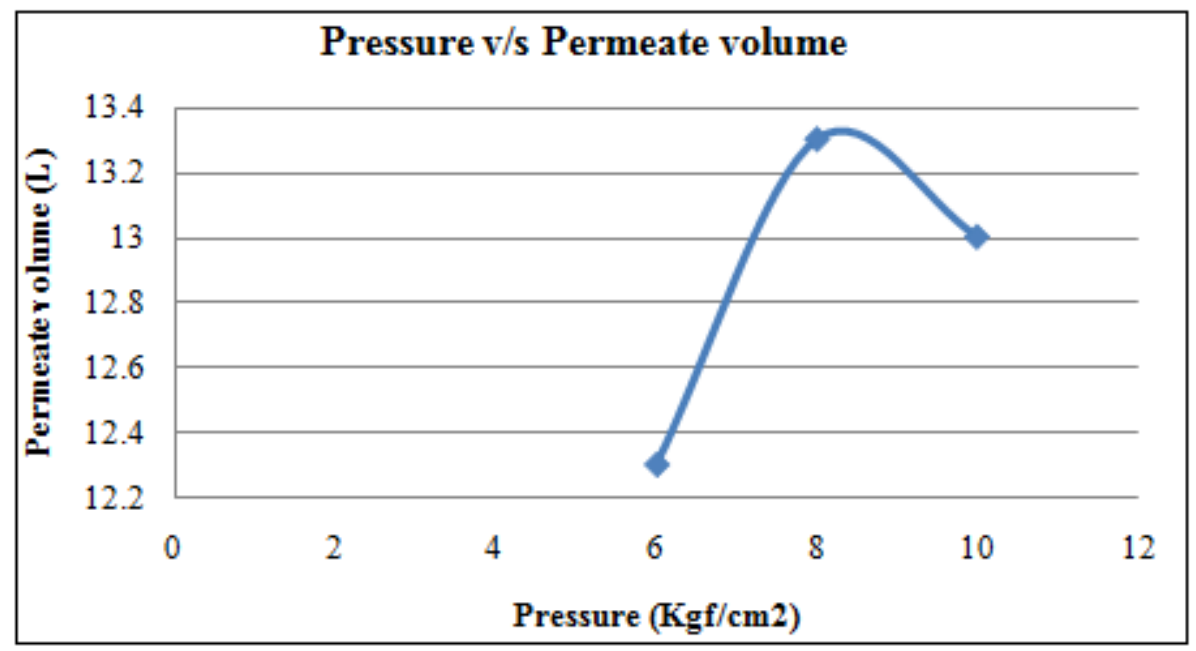

Figure 3: Effect of Pressure on volume of Permeate

Figure 4 shows Variation of Permeate Flux on Permeability.

It is observed that as permeate flux increases, permeability

increases.

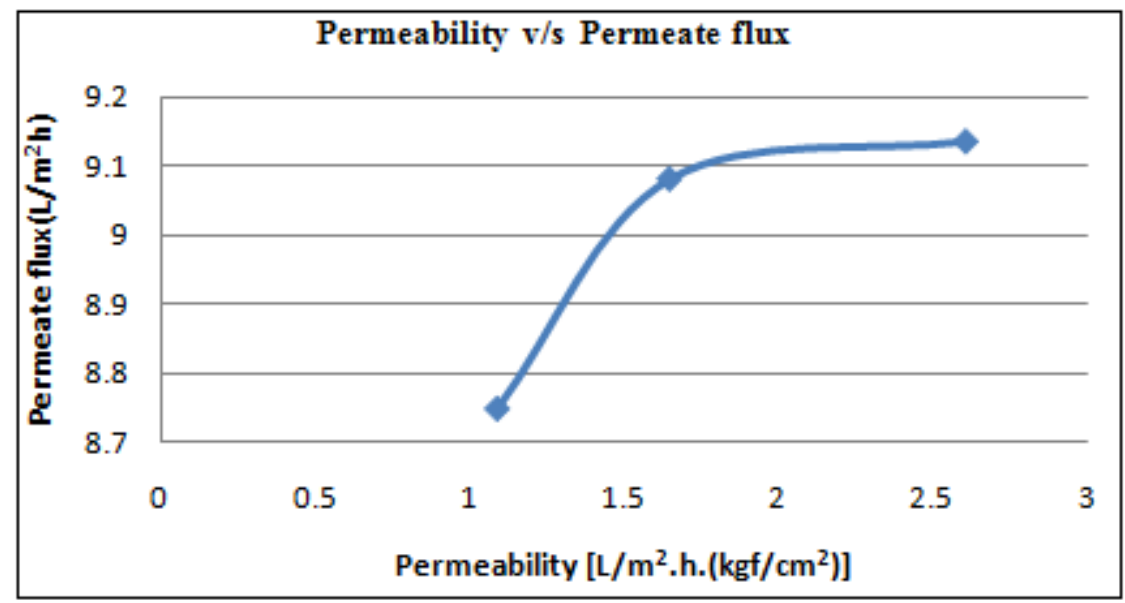

Figure 4: Variation of Permeate Flux on Permeability

\section{Conclusion}

In water recycling, where a multiple barrier approach may be required to lower the risk for water users, and the product water achieved using such technology would approach ultrapure water. It is hence essential to plan water recycling with an integrated water cycle approach and determine the most sustainable water usage. In the light of such results it appears unreasonable to assume that direct reuse of water for personal consumption is a sensible solution. However, if the discharge of moderately treated wastewater persists, one needs to realise that the global water cycle is closed and organic micro pollutants such as estrogen can reach our drinking water sources. It is essential that further 


\section{International Journal of Science and Research (IJSR) \\ ISSN (Online): 2319-7064}

Index Copernicus Value (2013): 6.14 | Impact Factor (2014): 5.611

developments optimise the reduced use of synthetic chemicals, effective removal as well as destruction of the removed estrogens. This work involved the evaluation of the retention of organic micropollutans such as synthetic estrogens from the EDCs group in the reverse osmosis membrane process. The application of reverse osmosis water treatment made it possible to remove the investigated estrogens to a high degree $(>95 \%)$, with the membrane made from polyethersulphone.

\section{Recommendations}

There is no established maximum contaminant level to address and estrogenic chemicals and others PPCPs are not classified as hazardous waste. Yet there is increasing evidence that they pose a mounting environmental health risk. There are many tactics which could be employed to control our exposure to estrogen. They can be broken down into consumer education, government regulation, medical innovation, proper disposal and effective filtration in wastewater treatment facilities. These approaches would focus on limiting the introduction of estrogenic chemicals into the environment and efficient removal of those introduced.

Consumers need to be made aware that these chemicals pose a health risk and they require proper handling and disposal. The government needs to adopt regulations to support this end. Estrogenic chemicals must be classified as hazardous waste. Unused birth control pills, used birth control patches, and unused hormone replacement therapy drugs should be part of drug take back" programs and either recycled or disposed of as medical waste by proper incineration.

Wastewater treatment plants must test for estrogen contamination before release of treated water back in the environment. If contamination exists, several filtration and treatment methods have proved effective.

\section{References}

[1] Baronti C, Curini R, D’Ascenzo G, Di Corcia A, Gentili A, Samperi R. Monitoring natural and synthetic estrogens at activated treatment plants and in receiving river water. Environ Sci Technol 2000;34:5059-66.

[2] Cheryan, M (1998). Ultrafiltration and Microfiltration Handbook. Lancaster, PA.: economic Publishing Co., Inc.

[3] Daughton CG, Ternes TA. 1999. Pharmaceuticals and personal care products in the environment: agents of subtle change? Environ Health Perspect 107:907-938.

[4] Johnson AC, Belfroid A, Di Corcia A. Estimating steroid oestrogen inputs into activated sludge treatment works and observations on their removal from the effluent. Sci Total Environ 2000;256:163- 73.

[5] Lange, I. G.; Daxenberger, A.; Schiffer, B.; Witters, H.; Ibarreta, D.; Meyer,H. H. D. (2002) Sex Hormones Originating From Different Livestock Production Systems: Fate and Potential Disrupting Activity in the Environment. Anal. Chim. Acta., 473, 27-37.

[6] Membranes on Polyolefins Plants Vent Recovery, Improvement Economics Program". by Intratec, ISBN 978-0615678917, Q3 2012
[7] TERNES T., Drugs and hormones as pollutants of the aquatic environment. Determination and ecotoxicological impacts, The Science of the Total Environment 225, 1, 1999.

[8] Ternes TA, Stumpf Mueller J, Haberer M, K, Wilken RD, Servos M. Behaviour and occurrence of estrogens in municipal sewage treatment plants-I. Investigations in Germany, Canada and Brazil. Sci Total Environ 1999a;225:81- 90 